\title{
For a rationalized refurbishment of the 1960s-70s towers: the Core-Skin-Shell concept
}

\author{
L. Arantes ${ }^{1,2,3}$, P. Rollet ${ }^{1,2}$, O. Baverel ${ }^{1,2,4}$ \& D. Quenard ${ }^{3}$ \\ ${ }^{1}$ Unité de Recherche AE\&CC, France \\ ${ }^{2}$ Laboratory CRATerre - ENSAG, France \\ ${ }^{3}$ Division Materials, CSTB, France \\ ${ }^{4}$ UR NAVIER, Ecole des Ponts Paris-Tech, France
}

\begin{abstract}
Cities are considered to be energy consumers, because of transport and buildings, which both make up almost $75 \%$ of the total energy consumption. In France, the most criticized buildings are the towers built during the 1960s and 70s. This paper aims to show an architectural concept that proposes to consider the sustainable refurbishment of towers, instead of their demolition. This concept is called the Core-Skin-Shell concept. The paper firstly describes the context that leads up to a sustainable renovation of 1960s existing real-estate. Then, it describes in detail the Core-Skin-Shell concept, which is based on a distinction of the building functions into three "stratums": the Core, which consists of the structure of the building and brings thermal inertia; the Skin, which is a heat shield and which ensures natural lighting and ventilation; and all around them, the Shell, which both protects against outside threats and produces energy from the sun or wind. Thanks to this layering, this concept expects to optimize every function of the building and to solve the two conflicting energy exigencies in buildings: reducing the size of the envelope to minimize heat losses, and increasing it to receive as much renewable energy as possible. To study this concept, a first work consisted of the analysis of a few architectural projects. It revealed some interesting potentials concerning energy production and losses, comfort and even architecture and space qualities. In conclusion, from this analysis, this paper shows that the Core-Skin-Shell concept enables great possibilities in energy saving and comfort in the case of tower refurbishment.
\end{abstract}

Keywords: towers refurbishment, building envelope, optimisation, Core-SkinShell. 


\section{Introduction}

Cities are considered to be energy consumers, because of transport and buildings, which both make up almost $75 \%$ of the total energy consumption and $47 \%$ of greenhouse gas emissions (CITEPA [1]). In France, building stocks include 65\% of buildings built before the first French energy policy (1975) [2]. Among existing real-estate, the 1960s housing towers are the most criticized ones, because of two main reasons. These towers were not only made with very little insulation, but they also cumulate architectural, living and social problems. Nowadays, due to these criticisms, only $1 \%$ of the French do not see any problem with living in a tower. Thus, more and more projects vote for their demolition, in order to replace them with "better" constructions.

This paper is in line with a Final Year Report in Architecture [3] dealing with attractive vertical urban densification. Convinced of towers' potentialities, it aims to show an alternative concept to tower destructions, and proposes to consider their sustainable refurbishment. This holistic concept is called the CoreSkin-Shell concept. It has a double goal: it firstly aims to contribute to reduce the energetic bill of existing consumer buildings, such as 1960s towers; secondly, it expects to reveal tower dwellings qualities, by improving lighting, atmosphere or simply spaces.

\subsection{Preferring tower refurbishment to their demolition}

The paper firstly describes the context that leads up to a sustainable renovation of 1960s existing real-estate. In France, for a few years, new buildings (which make up every year $1 \%$ of building stocks) have been subjected to many regulations, whereas the existing real-estate, which is 30 million accommodations [4], is by far the main energy saving potential sector.

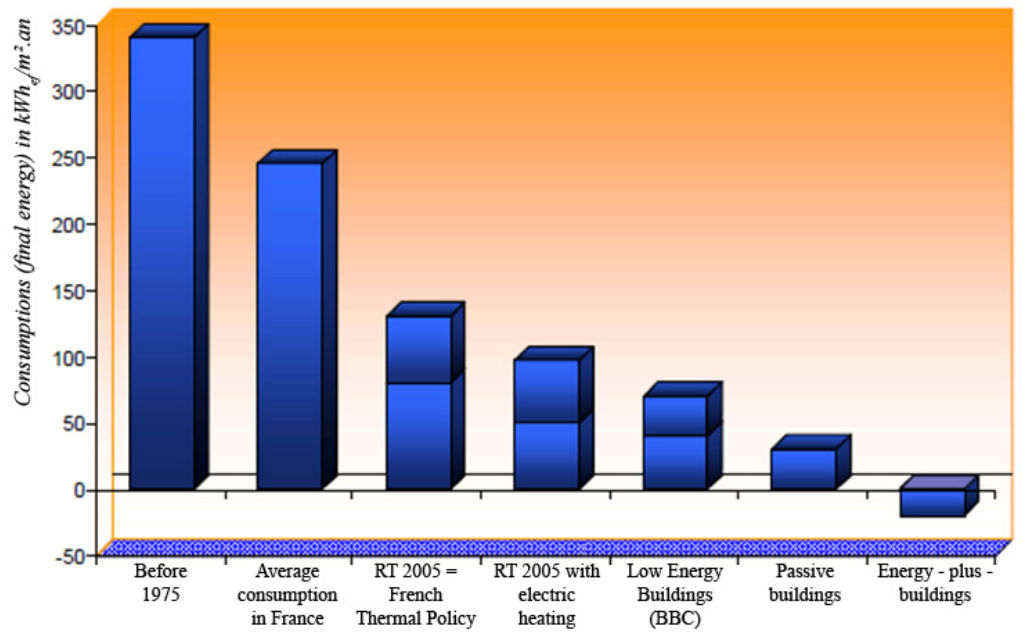

Figure 1: French heating consumptions for different buildings (CSTB, www.cstb.fr, 2007). 
Consuming almost $350 \mathrm{kWhef} / \mathrm{m}^{2}$ a year, the $1960 \mathrm{~s}-70$ s towers are among the most energy consuming buildings (fig.1). During the post-war years, the priority was mass accommodation rather than sustainability. As a consequence, towers were made with little or even no insulation. Today, towers are thus said to be "energetic wrecks" (ADEME [5]).

\subsection{Demolishing towers: a common French process that does not make sense anymore}

In France, through the policy called "demolishing-rebuilding", more and more projects plan to demolish several social housings built between 1950 and 1970, in order to solve the urban, architectural and social problems they are charged with: their monolithic forms create a monotonous and repetitive architecture, they are quite isolated from urban centres, and above all, social problems do not stop growing (lack of privacy, urban segregation, insecurity, etc.).

However, considering the housing and energy crisis, the demolishingrebuilding policy does not make sense anymore. On the one hand, such demolishing policies induce an important social cost. Five to six millions people are living in 1960s dwelling high buildings (Abbé Pierre Foundation [6]): demolishing their housings would necessitate finding them another accommodation, while France currently suffers from a lack of housing. On the other hand, the demolishing-rebuilding policy leads to many extra financial, energy and ecological costs. The French government spends $€ 167000$ to demolish and rebuild a dwelling (€17 000 for the demolition and $€ 150000$ for the construction), whereas refurbishing would be three to six times cheaper (Druot et al. [7]). In addition, demolitions lead to significant wastes: in the building industry, as $56 \%$ of wastes are due to demolitions (ADEME [8]).

Considering these facts, how could such a demolition policy be justified? Despite their shortages, the 1960s dwelling towers still store real qualities. Indeed, thanks to their morphology and their size, towers can house a huge number of families, while there is a lack of 800000 housings in France (Abbé Pierre Foundation, 2009). Moreover, even if the tower typology is very controversial, it offers important spatial and structural advantages: thanks to the height, there is no vis-à-vis and a clear view; towers are surrounded by green spaces; their structure is often sound; their façades are not load-bearing, and thus could be removed and lightened; etc.

\subsection{Refurbishing towers: a multiple-interest policy}

In that context, refurbishing existing real-estate becomes of economical, social, cultural and ecological interest. Nowadays, rehabilitation is booming: between 1996 and 2005, work expenses have risen by $40 \%$ only for rehabilitation (CNOA [9]). Most often, the renovation market is motivated by fiscal (reduced value added taxes) or statutory (disabled accessibility) factors. However, it also finds other inducements. First of all, the refurbishment has an ecologically important aspect. It is related to the necessity to reduce greenhouse gas emissions, to which the building industry contributes $20 \%$ [10]. The refurbishment could also answer 
social goals. In particular, architects and other planning professionals are facing some significantly changing lifestyles (population ageing, changing family unit, ecological concerns, etc.). To satisfy these changing mindsets, proposing extending and adapting accommodations is needed, in new as in existing realestate. In this context, the renovation can be judicious and useful.

\section{The Core-Skin-Shell concept: a holistic optimisation}

In this second part, the paper describes in detail the Core-Skin-Shell concept. Nowadays, the façade is considered to be a central and decisive sustainable component (Alexander Tzonis, in Ferrier [11]). Thus, architects face a new ecological and architectural challenge: inventing new building envelopes that fulfil multiple functions at the same time. Henceforth, the façade must be more than an insulating and lighting envelope. It must fulfil extra functions: production of energy, ventilation, distribution of electricity, etc. Every function, which was commonly hidden into sheathings and chimneys, is currently inserted in this area. As a result, building envelopes thicken.

However, in view of these new interests, the façade faces two conflicting energy exigencies in buildings. On the one hand, it is important to reduce the size of the envelope to minimize heat losses. On the other hand, increasing it is needed in order to harvest as much renewable energy as possible. The CoreSkin-Shell concept proposes to answer this new double functional constraint.

The Core-Skin-Shell concept was first proposed by Daniel Quenard [12]. This concept is a holistic architectural concept, based on the hypothesis of a distinction of the building functions into three "stratums".

\subsection{The Core}

The Core is the living volume of the building. It usually has an important mass, which brings thermal inertia. It could thus contribute to regulate temperature and inside comfort. Usually, the Core is the structure of the building. The Core of the multi-storey building is shown at the top of the figure 2 .

\subsection{The Skin}

The Skin is shown in the middle of figure 2. It is a heat shield that ensures both air tightness and thermal insulation. Moreover, it also provides natural lighting and ventilation, which are two essential indicators of a building's quality. Thanks to the diversity of its materials, it can create different atmospheres and spaces. It is thus linked with the protection and the comfort of the inhabitants.

\subsection{The Shell}

The Shell surrounds the Core and the Skin. On the one hand, the Shell consists of a shield that protects the building and its dwellings against outside threats. It thus ensures that the building is sound and perennial. On the other hand, it can become responsive and harvest energy from sun or wind. It is shown at the bottom of the figure 2 . 


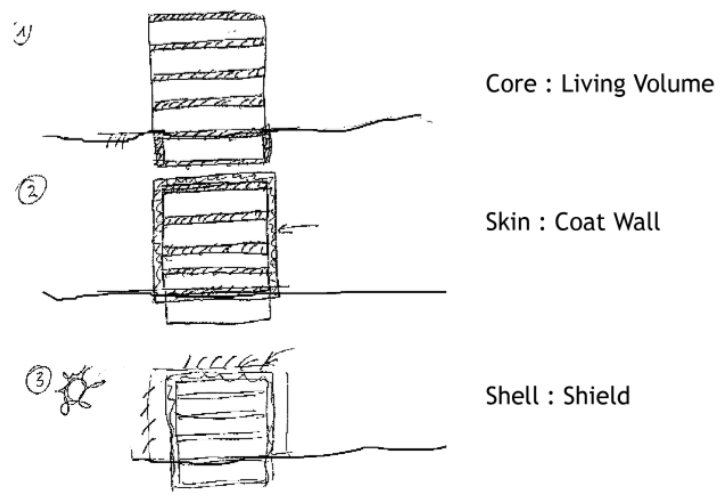

Figure 2: $\quad$ The distinction in three layers (Pélegrin [13]).

\section{Two case studies: the refurbishment of the Bois-le-Prêtre Tower and the one of the Three Towers of Grenoble}

\subsection{The refurbishment of the Bois-le-Prêtre Tower}

To study this concept, a first work consisted of the analysis of a few architectural projects. Among them, one of the best examples is the Bois-Le-Prêtre Tower rehabilitation and more specifically the proposal of Frédéric Druot, Anne Lacaton and Jean-Philippe Vassal. This project, called "Faire plus par l'extension", well illustrates the Core-Skin-Shell concept applied to a refurbished tower.

\subsubsection{The Bois-le-Prêtre Tower}

The Bois-le-Prêtre Tower is situated on the boundaries of Paris, Clichy and Saint-Ouen in France. It was built in 1959 by the architect Raymond Lopez. In 1990, it was renovated: the facelift only consisted of adding a little insulation. In 2006, the Paris local authority landlord (OPAC) announced a competition for a second refurbishment of the Tower.

This contest is the result of an architectural and energetic inventory of the Tower. Concerning energy consumptions, before any refurbishment, the Tower consumed $250 \mathrm{kWh} / \mathrm{m}_{\mathrm{Hab}}^{2}$ per year (Paris local authority landlord, www.parishabitatoph.fr, 2007). It was thus ranked into the E class in the French buildings' energy performance diagnosis, which corresponds to quite energyconsuming buildings.

Then, with regard to architecture and comfort criteria, several criticisms could be made. The structure was sound, the façades were not load-bearing, and the view was clear. The bad points were that the façades were made with asbestos, the dwellings were quite tiny, and most of them were not step-free access served. 


\subsubsection{The project of Frederic Druot, Anne Lacaton and Jean-Philippe Vassal: an illustration of the Core-Skin-Shell concept}

Considering these reports, the Paris landlord appealed for a total metamorphosis of the Tower. The projects should aim to improve spaciousness and relationships, to diversify typologies and to enhance inhabitants' behaviours. Among the six teams of architects entering the lists, the team composed of Frédéric Druot, Anne Lacaton and Jean-Philippe Vassal won the competition. With their "Faire plus par l'extension" project, they partly proposed to add huge extensions to the dwellings: either heated extensions on the gable sides, or outside terraces on lateral façades (fig. 3, left).

In this project, the Core-Skin-Shell concept is applied in a light way: the project keeps the heavy structural core of the Tower, whereas the skin and the shell are lighter and more transparent (fig. 3, right).

The Core includes the framework of the Tower (reinforced concrete floors and bearing walls), lift shafts and stairwells.

The Skin consists of the new façades of the Tower. The existing façades are removed and replaced by high picture windows, which open the views. To ensure the thermal insulation, the windows are doubled by insulating curtains.

Finally, the Shell consists of a polycarbonate shield that envelops the Tower. Thanks to moving panels, the shell can be manually opened and closed. Quite deep, the shell expects to create extra outside spaces. Moreover, it is supported by a metallic structure. Thus, it does not load the existing building. Thanks to removable curtains, the dwellings can be shaded. In this example, the architects made the choice not to produce energy.
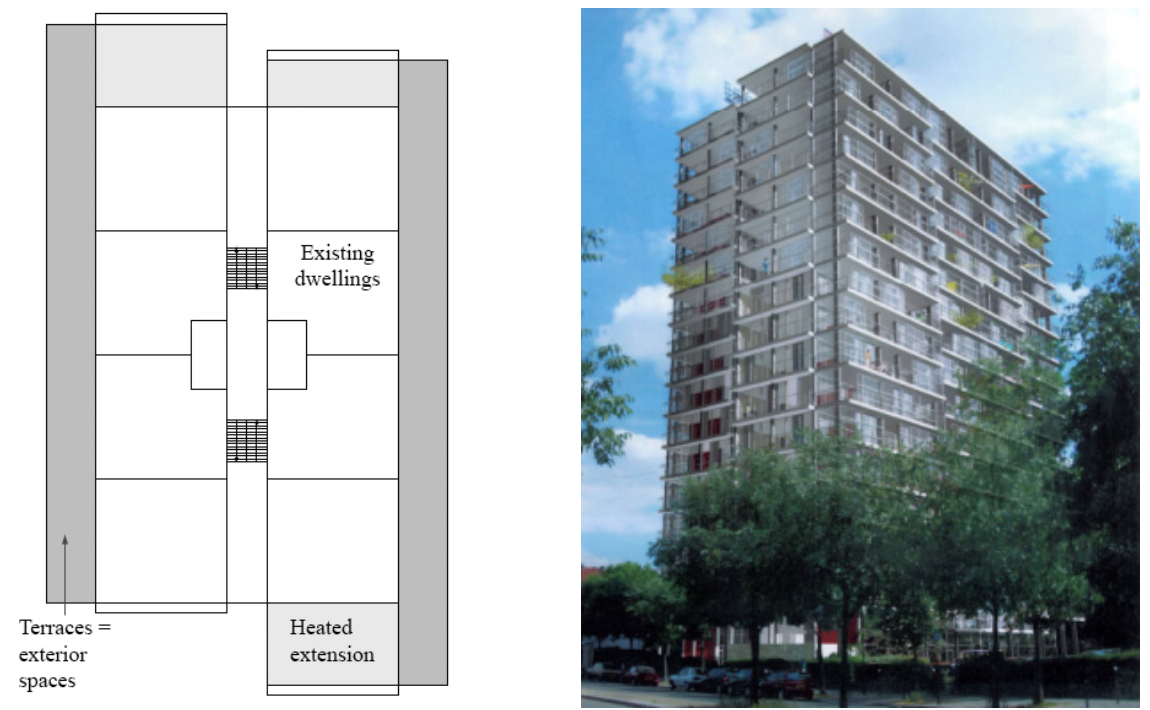

Figure 3: "Faire plus par l'extension" project: plan (left) and perspective (right). 


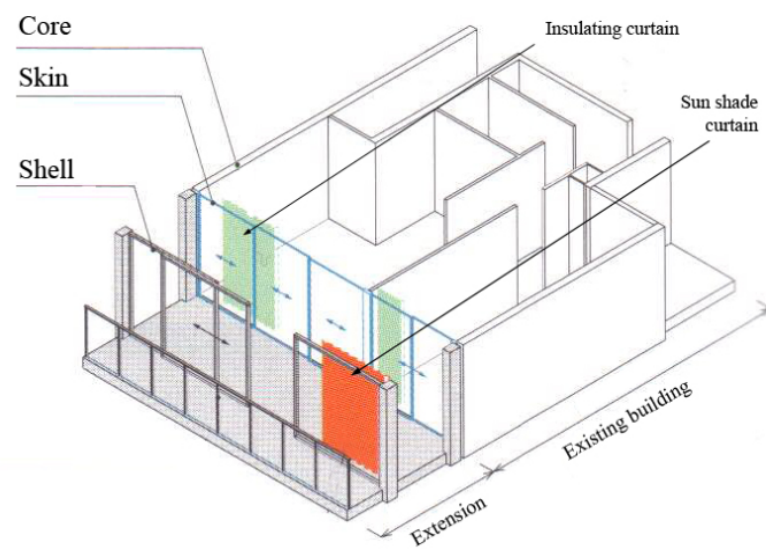

Figure 4: Perspective view (Druot [6]).
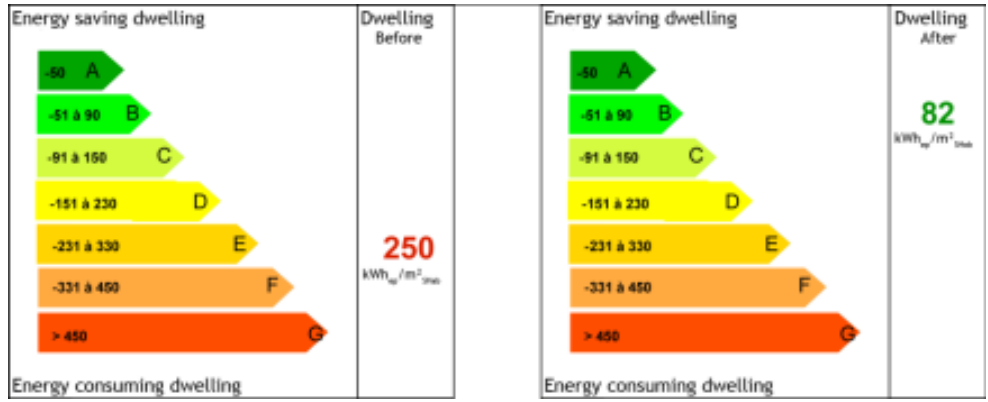

Figure 5: The Bois-le-Prêtre Tower annual consumption before (left) and after (right) refurbishment (Paris local authority landlord, www.parishabitatoph.fr, 2007).

\subsubsection{Spaces and energy results}

Thanks to this layering, the architects succeed in extending the dwellings' surfaces. They proposed an improving metamorphosis that enhances this Tower's hidden qualities. Thanks to the extensions, living surfaces are bigger: every dwelling increasing from 24 to $48 \mathrm{~m}^{2}$.

Moreover, the architects also succeeded in reducing by three the energy consumptions of the Tower: they are now valued at $92 \mathrm{kWhep} / \mathrm{m}^{2}$ per year. The Bois-le-Prêtre Tower is thus ranked into B class (fig. 5). However, the architects made the choice not to install energy production equipment, which could have even further reduced the energy consumption.

\subsection{The refurbishment of the Three Towers of Grenoble, France}

A second analysis on the Core-Skin-Shell concept consisted in the conception of an architectural refurbishment project, on the Three Towers of Grenoble. This work was done for an academic work in Architecture dealing with sustainable and attractive urban density (Arantes [1], Chalencon and Hadj Hassine [14]). 


\subsubsection{The Three Towers of Grenoble}

The Three Towers of Grenoble are three emblematic 28-storied towers in Grenoble. They were built between 1963 and 1967 and designed by the architects Roger Anger and Pierre Puccinelli. Their main characteristic is their rough façades, which avoid vis-à-vis between the dwellings (fig. 6, left). Thanks to this dynamic façade, each tower seems to be made with split-level apartments. Each tower counts around 168 accommodations in a living space of $12400 \mathrm{~m}^{2}$.

Notwithstanding, the Three Towers are currently criticized because of their high energy consumption. Because of their roughness (fig. 6, left), the external heat exchange façades are important compared to a smooth façade: the consumptions are assessed at around $264 \mathrm{kWh} / \mathrm{m}^{2}$ per year (Arantes [1]). The main losses are due to the North and South gable openings (fig. 7, left). The Three Towers thus rank in the E class.

In addition, spaces are sometimes criticized by some inhabitants: they notably complain of living in some kind of "box", especially concerning the balconies which are tiny $\left(4 \mathrm{~m}^{2}\right)$ and quite enclosed.

\subsection{2 "Intensités et extensions": the refurbishment of the Three Towers of Grenoble}

Following the broader reflexion on attractive vertical density, five projects have been hatched in order to improve the Three Towers energy consumption and also to provide (outdoors) extra comfort spaces. Among them, the project "Intensités et extensions" (fig. 6 right, 7 right) gives a good architectural compromise.

Figure 7 shows a plan of a renovated floor (on the right). For each tower, the project "Intensités et extensions" proposes to keep the existing framework, that is to say the reinforced concrete floors and bearing walls. The stairs are also kept
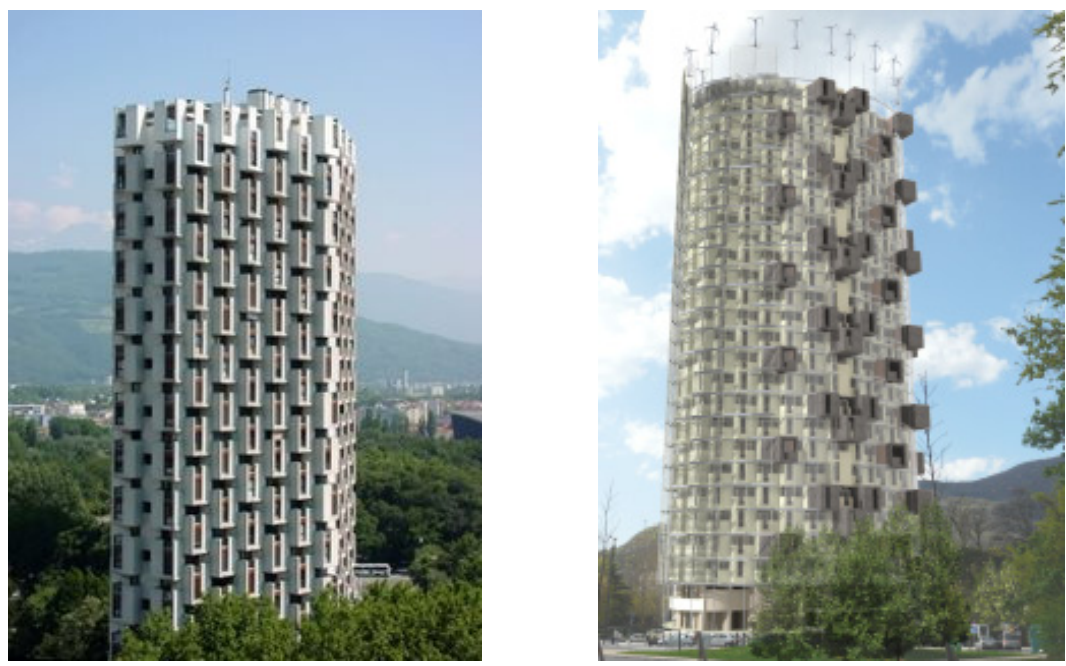

Figure 6: The Three Towers before (left [15]) and after (right [1]) refurbishment. 

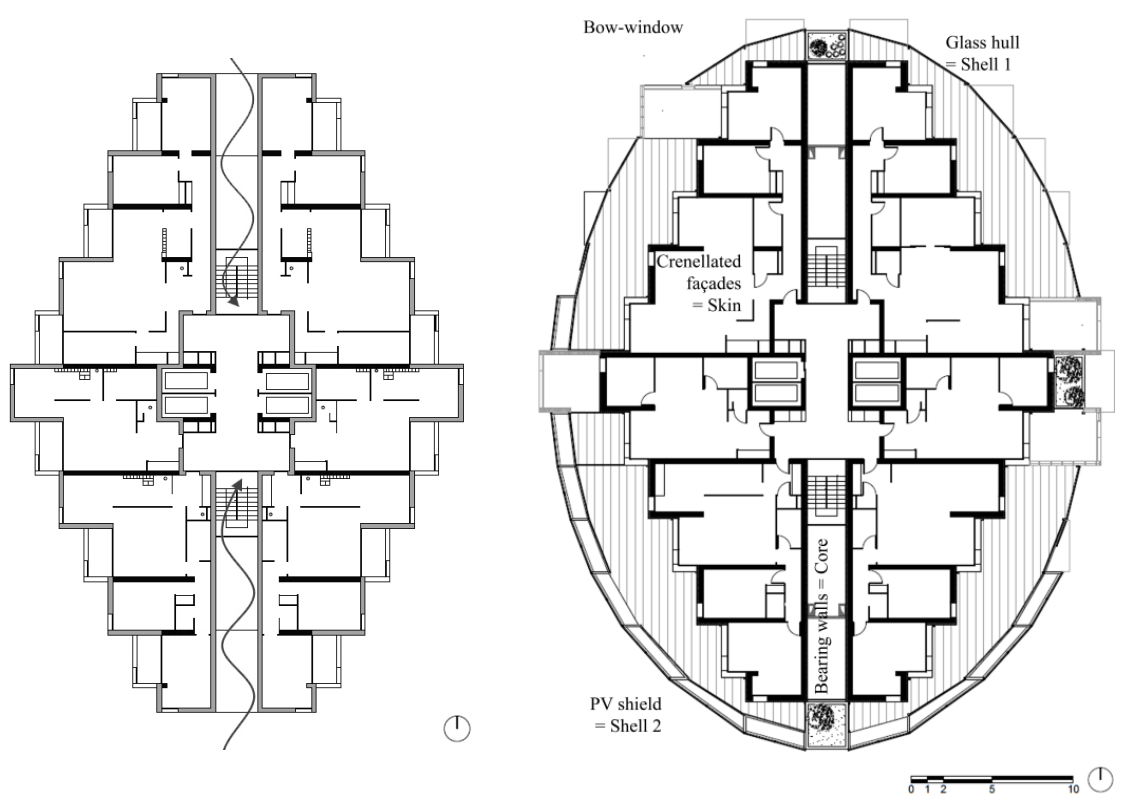

Figure 7: Plan of a Tower before (left) and after (right) renovation (Arantes [1]).

but their gable walls are enclosed with windows, so that the wind does not come in anymore. External surfaces are thus reduced. All these elements constitute the Core of the tower.

The façades are also kept as they were. Only balconies are closed and counted into the inside living space. The whole is insulated at the exterior. Insulated façades and inserted balconies constitute the Skin of the tower.

A Shell is proposed all around the tower (fig. 8). This shell creates huge terraces for every dwelling. The terraces are punctuated with some bowwindows. The origin architecture is thus preserved. Concerning the shell, it includes two different elements: a glass and transparent shell all around the tower, and a photovoltaic shield that doubles the glass hull on West to SouthEast façades. Thanks to the glass shield, dwellings and terraces are protected from wind, rain and bad weather. The second shield, made with photovoltaic panels, harvests the sun energy and then produces electricity. During summer, the panels are used as sun shades and protect against direct sun rays and overheating.

\subsection{3 "Intensités et extensions": space and energy results}

As a result, this project could enhance the living quality on several points. First, by closing the towers' gables and reinforcing the insulation, this project succeeds in reducing the energy consumptions by $60 \%$. The new consumptions are valued at $107 \mathrm{kWh}$ ep $/ \mathrm{m}^{2}$ per year. This reduction is due to the fact that the "new" tower is more compact than the existing one. In addition, the "form coefficient" also 

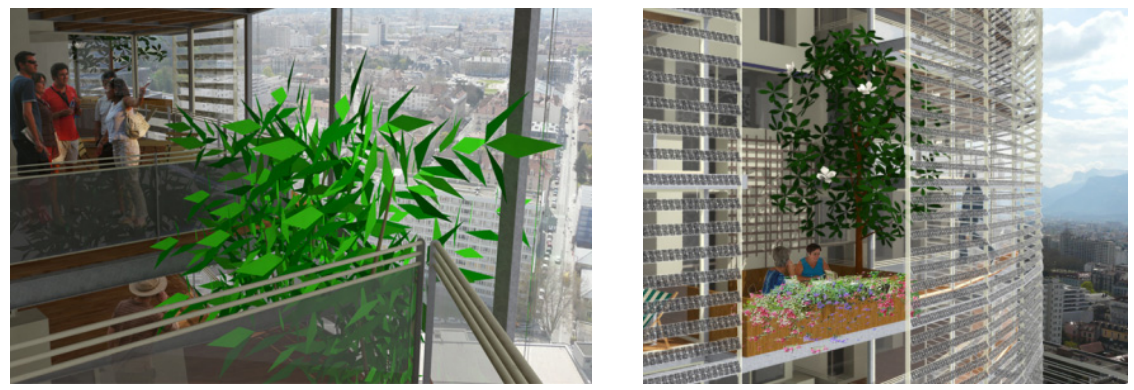

Figure 8: The Shell: the glass hull (left) and the photovoltaic shield (right).

decreases. This coefficient is given by the external façades divided by the heated volume (Ratti [15]). A reckoning shows that the form coefficient for the new project is half the one of the existing tower. These results are related to the reduction of the energy consumption.

Second, by creating extra inside spaces, the living heated space rises by $26 \%$ and reaches $15800 \mathrm{~m}^{2}$ in a tower. In addition, the Shell is a means to create generous exterior spaces (fig. 8): thanks to the project, $10000 \mathrm{~m}^{2}$ terraces are built in a tower. On average, each accommodation is embellished with a $60 \mathrm{~m}^{2}$ panoramic terrace.

Third, thanks to many windows and to the shell's high windows, the dwellings are well-lit and have a clear overall view towards Grenoble and its mountains. The windows of the Skin layer represents $40 \%$ of the façades.

Forth, the surrounding active shell contributes to reduce the energy consumption of the Three Towers. For one tower, production is assessed at almost $285000 \mathrm{kWh}$ per year. This production fulfils the electric needs of a tower (specific electricity, artificial lighting and common spaces lighting).

\subsection{The Core-Skin-Shell concept's potentialities}

Finally, in view of these two architectural examples, this first analysis revealed some interesting potentials concerning energy production and losses, comfort and even architecture and space qualities.

\subsubsection{The Core-Skin-Shell applied to renovation: a light intervention}

Foremost, applying the Core-Skin-Shell concept to the towers' refurbishment is interesting because it consists of a light intervention, with only few demolitions. By keeping the existing framework and adding an external structure, the works inside the dwellings are negligible. So, the inhabitants can keep on living in their apartment. There is little temporary accommodation, unless a dwelling needs heavy work.

\subsubsection{Improving the towers' energy performances}

In addition, thanks to the Core-Skin-Shell layering, each layer of the façade can be singly conceived and optimised. In the examples, the Core consists of the 
concrete structure of the tower. Concrete brings thermal inertia and contributes to regulating the temperature inside the dwellings.

Concerning the Skin, it can be considered without any outside restraint or contribution (like bad weather, wind or sun): its role is only to insulate the dwellings and it is conceived accordingly. As a result, the architect can adjust its shape and its components. Thanks to these two elements, the 1960s towers' energy consumptions can be reduced.

The Shell takes new technical equipments, which provide a new roughness. These equipments harvest energy from the sun or wind. They actively contribute to reduce the energetic bill of the existing towers. Moreover, the shell also has a passive role, since it creates a buffer zone between it and the skin. So, the temperature gradient and the heating needs are reduced.

\subsubsection{Spacious dwellings and extra spaces}

Lastly, by separating the Shell from the Skin, an extra space can be created. The Shell establishes a semi outside space with comfortable climatic conditions. The atmosphere is temperate, and above all protected from wind and rain. It is a kind of exterior space inside the glass shield, which behaves like a micro climatic envelope. Furthermore, the extra interior-exterior spaces form huge terraces that are still missing in dense urban centres.

\section{Conclusion}

In conclusion, from this analysis, this paper shows that the Core-Skin-Shell concept enables great possibilities in energy saving and comfort in the case of tower refurbishment. Its main advantage is to keep the existing structure, which is important considering the height of towers. Even though such a refurbishment seems to be quite difficult, it is less expensive than a demolishing-rebuilding project (Druot [3]).

Many times, the Core of the building exists. An appropriate Skin has to be designed. The Shell must also be totally created all around the tower or only on a part of it. This concept could thus interest people who want to preserve a legacy tower, as is the case for the Three Towers of Grenoble, that have recently been listed in the French "XXth century Architectural Patrimony".

Currently, the Core-Skin-Shell concept is still under study as part of a PhD in architecture, held by Laetitia Arantes and conducted by Hubert Guillaud and Pascal Rollet. It will be more accurately analysed and quantified, in particular concerning energy saving, heating, lighting and air quality.

\section{Acknowledgements}

This study results from an academic work in Architecture dealing with sustainable and attractive urban density. We would like to acknowledge the two other co-authors of this academic work: Elodie Chalencon and Yacine Hadj Hassine. Moreover, the $\mathrm{PhD}$ this paper results from also benefits from the supervision of two French architects: Hubert Guillaud (Architect, HDR - French 
post-doctoral degree allowing its holder to supervise PhD students, Director of the French Laboratory "Architecture Environnement et Cultures Constructives") and Pascal Rollet (Architect, MA.Arch.UC Berkeley, professor ENSA Grenoble). We would like to acknowledge them. Finally, this paper has also benefited from comments and corrections from Anne-Monique Bardagot. We would like to thank her.

\section{References}

[1] CITEPA (Centre Interprofessionnel Technique d'Etudes de la Pollution Atmosphérique), http://www.citepa.org

[2] http://www.domelio.fr

[3] Arantes, L., Intensités urbaines, La densification verticale comme potentiel architectural éco-responsable, Final Year Report conducted by Pascal Rollet, ENSAG, 445 p., 2009

[4] Quenard, D., Vers l'autonomie énergétique pour se loger et se déplacer?, Univertsité d'été - Sauvons le climat, Cabourg, 2008

[5] ADEME (Agence De l'Environnement et de la Maîtrise de l'Energie), http://www2.ademe.fr

[6] Abbé Pierre Foundation, L'Etat du mal-logement en France, annual report, 294 p., 2009

[7] Druot, F., Lacaton, A. \& Vassal, J.P., Plus, Les Grands ensembles de lodgements, Territoire d'exception, Editions Gustavo Gili, 264 p., 2007

[8] La Lettre ADEME, n77, June-July 2001, http://www2.ademe.fr

[9] Conseil National de l'Ordre des Architectes (CNOA), "Réhabiliter: un enjeu pour demain", www.manifesterpourlesvilles.com

[10] Tessonniere, F., 'La Réhabilitation: une notion essentielle pour le 'durable'. Exemple de la Cité Universitaire La Colombière, Montpellier”, Séminaire PoSt-FossiLe, 34 p., 2009

[11] Ferrier, J., Architecture = Durable, 30 architectes, 30 projets en Ile-deFrance, 264 p., 2008

[12] Quenard, D., CSSB Project, Core-Skin-Shell Building, CSTB, Feb. 2007

[13] IMPACTE, Innovation Maîtrisée Pour l'Architecture Climatique, la Thermique et l'Environnement, www.chantier.net, 2007

[14] CHALENCON, E., HADJ HASSINE, Y., Tours Eco-Nomes, Nouvelles formes d'habiter en centre urbain dense, Final Year Report conducted by Pascal Rollet, ENSAG, 189 p., 2009

[15] www.grenoblecmieux.com

[16] Ratti, C., Baker, N. \& Steemers, K., "Energy consumption and urban texture", Energy and Buildings, Vol.37, Iss.7, pp.762-776, 2005

[17] Fernandez, P., Lavigne, P., Concevoir des bâtiments bioclimatiques, Fondements et méthodes, Editions Le Moniteur, 430 p., 2009 